\title{
CHRONIC RADIATION ENTERITIS PRESENTED AS SMALL INTESTINAL OBSTRUCTION: A CASE REPORT AND REVIEW OF LITERATURE
}

\author{
Subrat Kumar Soren¹, K. Suhas², K. Sivarama Prasad³, G. Vidyasagar4
}

\begin{abstract}
HOW TO CITE THIS ARTICLE:
Subrat Kumar Soren, K Suhas, K Sivarama Prasad, G Vidyasagar. "Chronic radiation enteritis presented as small intestinal obstruction: a case report and review of literature". Journal of Evolution of Medical and Dental Sciences 2013; Vol2, Issue 36, September 9; Page: 6933-6937.
\end{abstract}

\begin{abstract}
Chronic radiation enteritis (CRE) is a complication of radiation therapy for cancer, most commonly for rectal, prostate and pelvic malignancies. It can affect both the large and small intestine, is often progressive, and may lead to a variety of clinical consequences (such as diarrhea, nausea, weight loss, abdominal pain, intestinal obstruction, perforation, abdominal abscess and fistula) depending upon the extent of injury. It usually develops six or more months after radiation therapy. This contrast with the timing of acute radiation enteritis (characterized by diarrhea and abdominal pain), which develops during shortly after radiation therapy and resolves within two to six weeks. Chronic radiation enteritis usually develops only after large doses of radiation therapy have been delivered (4500 to 5500cGY). Intestinal injury is believed to oxidative damage caused by the formation of free radicals. The primary pathophysiologic pathway of CRE is obliterative endarteritis that leads to intestinal ischemia resulting in stricture, ulceration, and occasionally fistula formation. Management for the chronic enteritis is always conservative unless severe complication is warranted. We present a case of acute intestinal obstruction following radiation therapy for cervical malignancy after six months.
\end{abstract}

KEY WORDS: Chronic radiation enteritis, stricture, endarteritis obliterans.

INTRODUCTION: Indeed, the first medical report of radiation injury to GI tract was described by Walsh in 1897 just 2 years after the first description of the use of x-ray by Roentgen [1]. Radiation enteritis is an unintended consequence of the treatment of intra abdominal and pelvic malignancies. Radiation enteritis can be further classified as acute or chronic, based on the symptomatology presentation in proximity to the time of radiation therapy. Acute radiation enteritis characterised by diarrhea and abdominal pain which develops during or shortly after radiation therapy and resolves within two to six weeks. The reported incidence of acute radiation enteritis (ARE) is quite variable reports from $20 \%$ to $80 \%$. [2]

Chronic radiation enteritis may present from months to decades after a course of Radiation therapy. The incidence of CRE estimated from $6 \%$ to $78 \%$. [3-5].

CASE REPORT: A 65 years female with previous history of radiation therapy for carcinoma of Cervix with stage Ib, treated seven months back, presented to our emergency department with complaining of severe abdominal pain and bilious vomiting. There was associated with abdominal distension and constipation suggestive of intestinal obstruction. There was history of frequent passage of loose motion associated with mucus only. Patient was habituated with smoking for 30 years. On general examination patient was afebrile, Hypertensive and there was pallor and bilateral pedal edema. On abdominal examination abdomen was distended. Also abdomen was tender (diffusely) and presence of ascitis. Ultrasonography revealed dilated bowel without peristalsis and plain x-ray of 
abdomen erect posture showed multiple air fluid levels. [Figure-1]. After baseline investigation patient was treated initially with conservative approach but symptoms did not subside. So patient was explored after correction of anemia and hypoproteinemia.

On exploration, it was found proximal dilated small intestinal loops and two stricture located in the terminal ileum, one at $5 \mathrm{~cm}$ and other $15 \mathrm{~cm}$ from ileocaecal junction [Figure-2]. Rest of the bowel loops are within normal limit except ascitis. Resection of terminal ileum encompassing both the strictures and then ileo-ascending colon, side to side with two layered anastomosis done.[figure-3]. Post operative period was uneventful. Abdominal sutures are removed at $10^{\text {th }}$ post operative day. After 3 months of follow-up patient was asymptomatic except early few days of loose motions which was treated with dietary modifications and lactobacillus sachet.

DISCUSSION: Radiation enteritis describes the pathophysiology and clinical manifestation of radiation injury to the small intestine and the colon and is more commonly seen in terminal ileum which is relatively fixed, in comparison to the jejunum and proximal ileum [6].

Acute radiation enteritis presents during or shortly after a course of radiation therapy and typically presents with nausea, vomiting, diarrhea and abdominal pain. These symptoms may be seen with radiation doses of 5 to 12 Gy but usually resolve within 3 months of completion of radiation. ARE is considered a self limiting clinical entity and only affected to mucosa. The reported incidence of ARE is quite variable and ranges from $20 \%$ to80\% [2].

In contrast, chronic radiation enteritis (CRE) may present from months to decades after a course of radiation therapy. The presentation of CRE is variable and may manifest as malabsorption, acute and chronic gastrointestinal haemorrhage and abdominal pain from obstruction, ulceration. The syndrome of CRE reflects transmural damage to the bowel by radiation. The incidence of CRE is estimated $6 \%$ to $68 \%$ [6-8]. Symptomatic radiation damage is seen in $50 \%$ of patients who receive range of 45 to 65 Gy to the small intestine [7]. Tissue factors such as cell growth and replication rates, local oxygen tissue versus and genetic susceptibility contribute to the development of radiation enteritis. Co-morbid illness of the individual patient such as smoking, diabetes, hypertension and atherosclerotic disease may also potentiate radiation effects [6].

The pathophysiologic effects of CRE include mucosal ulceration, epithelial atypia, ileitis cystic profunda, serosal thickening, endarteritis obliterans, intestinal fibrosis and lymphatic congestion. Vascular damage is the primary pathophysiologic pathway of late-radiation enteropathy [8].

The diagnosis of CRE is established by suggestive radiologic findings in patients with compatible clinical features who have a history of prior radiation exposure. Enteroclysis is the most accurate imaging test for diagnosing chronic radiation enteritis, with reported sensitivity and specificity greater than 90\% [9]. Computed tomography (CT) of the abdomen is not helpful in the precise diagnosis of radiation enteritis because the CT findings are non specific. However it is a valuable procedure to diagnose high grade bowel obstruction resulting from abdominal metastasis. Despite some controversy, CT enteroclysis may be the best single test when clinical presentation is an acute or intermittent obstruction [10]. CT enteroclysis has been reported to have a greater sensitivity (89\%) and specificity (100\%) than CT in patients suspect to have a partial small bowel obstruction [11]. The differential diagnosis for CRE may be Crohn`s disease, intestinal tuberculosis, bands and adhesions, typhoid enteritis etc. 
The treatment of CRE represents a formidable challenge. Surgery for this condition is difficult; it is always associated with high morbidity rates and should be avoided in the absence of specific indications such as high grade obstruction, perforation, haemorrhage, intra abdominal abscess, and fistula. Furthermore it is difficult to differentiate normal and irradiated segment intraoperatively or frozen section analysis, because anastomosis between irradiated segment of intestine are associated with leak rates as high as 50\%. [12]

When one end of the anastomosis normal tissue, the risk of an anastomotic leak is considerably reduced [13].

It is still controversial which operative procedure is optimal for management of radiation enteritis. $[12,14]$

In conclusion limited resection of the diseased intestine is the goal but if the lesion is too diffuse a bypass procedure may be attempted.

\section{REFERENCES:}

1. Walsh D: Deep tissue traumatisation from roentgen ray exposure. Br Med J 2:272,1897

2. Weijers RE, Vander jagt EJ, Jansen W: Radiation enteritis: an overview. Fortschr Roentgenstein 152:453,1990

3. Potosky A, Legler J, Albertsen P, et al: health outcomes after prostatectomy or a radiotherapy for prostate cancer: J Natl Cancer Inst 92:1582, 2000

4. Kollmargen C, Meagher A, Wolff B, et al; long term effect of bowel obstruction. Ann surg 220:679, 1994

5. Grami B, Harrington $\mathrm{K}$, Blake $\mathrm{P}$, et al: how patients manage gastrointestinal symptoms after pelvic radiotherapy. Aliment pharmacol ther 18:987,2003

6. Green S, Stock RG, Greenstein AJ: Rectal cancer and inflammatory bowel disease: natural history and implication for radiation therapy. Int J radiation oncology. Biol phys 44:835, 1999.

7. Rubin P, Cararett G: A direction for clinical radiation pathology: the tolerance dose. In vaeth JM, editor; frontiers of radiation therapy and oncology, vol 16. Baltimore, 1972, university park press, $\mathrm{p} 1$.

8. Rodier JF: radiation enteropathy-incidence, etiology, risk factors, pathology and symptoms. Tumori supplement 81:122, 1995

9. Dixon PM, Raulston ME, Nolan DJ. The small bowel enema: a ten year review. Clin radiology 47:46,1993

10. Bander GN, Maylinte DDT, Kloppel VR, et al CT enteroclysis; a superfluous diagnostic procedure or valuable when investigating small bowel disease? A J R Am J Roentgenol 172:373, 1999.

11. Walsh DW, Bander GN, Timmons JH. Comparison of computed tomography in the setting of suspected partial small bowel obstruction. Emerg radiol 5:29, 1998

12. Hendrix P, Cahow E. Chronic radiation enteritis. Gastroenterologist 2:70, 1994.

13. Galland RB, Spencer J. Surgical management of radiation enteritis. Surgery 99:133, 1986.

14. Nakashima $\mathrm{H}$, Veo $\mathrm{H}$, Shibuta $\mathrm{K}$, et al surgical management of patients with radiation enteritis. Int surg 81:415,1996 


\section{CASE REPORT}
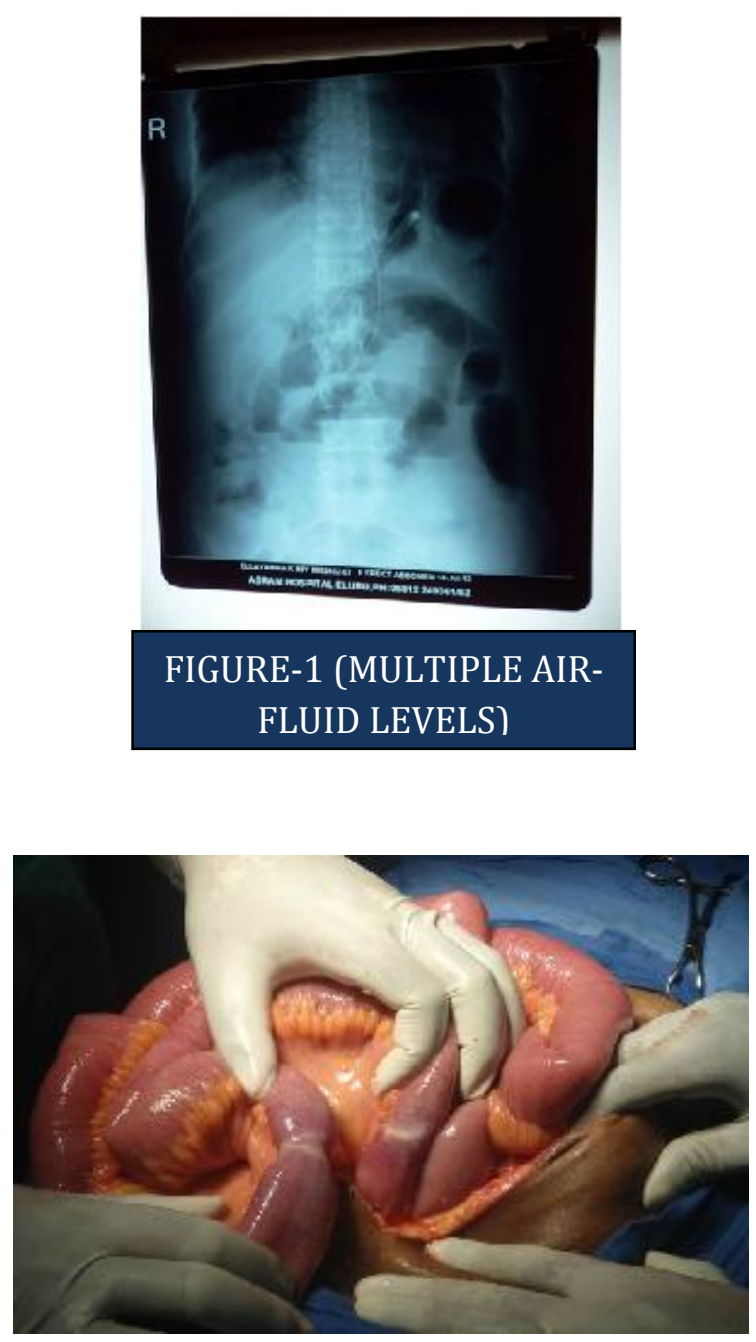

FIGURE-2 (TWO STRICTURES AT TERMINAL ILEUM)

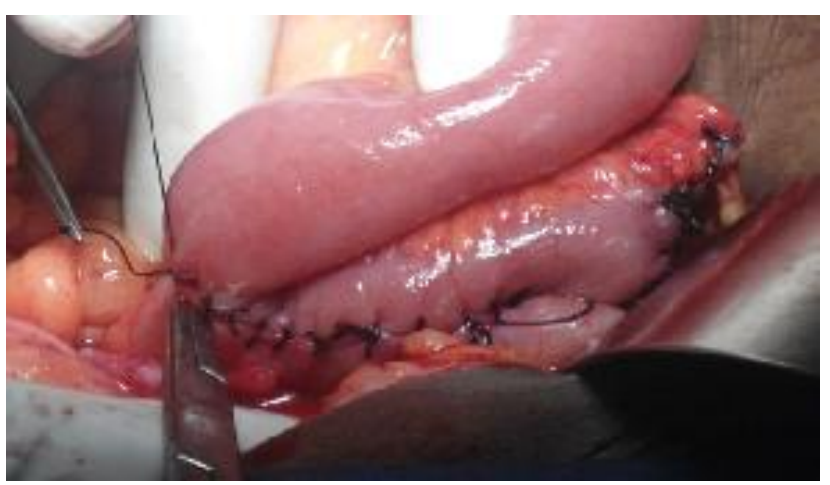

FIGURE-3 (ILEO-ASCENDING COLON TWO LAYERED SIDE TO SIDE ANASTOMOSIS) 


\section{AUTHORS:}

1. Subrat Kumar Soren

2. K. Suhas

3. K. Sivarama Prasad

4. G. Vidyasagar

\section{PARTICULARS OF CONTRIBUTORS:}

1. Assistant Professor, Department of General Surgery, ASRAM Medical College, Eluru, West Godavari Dist, Andhra Pradesh.

2. Associate Professor, Department of General Surgery, ASRAM Medical College, Eluru, West Godavari Dist, Andhra Pradesh.

3. P.G.T, Department of General Surgery, ASRAM Medical College, Eluru, West Godavari Dist, Andhra Pradesh.
4. P.G.T, Department of General Surgery, ASRAM Medical College, Eluru, West Godavari Dist, Andhra Pradesh.

\section{NAME ADDRESS EMAIL ID OF THE CORRESPONDING AUTHOR:}

Dr. Subrat Kumar Soren,

Assistant Professor, ASRAM Medical College, Eluru, West Godavari, Andhra Pradesh - 534005.

Email-drsubratsurgery@gmail.com

Date of Submission: 30/08/2013.

Date of Peer Review: 31/08/2013.

Date of Acceptance: 02/09/2013.

Date of Publishing: 04/09/2013 